\title{
INVESTIGATION AND TREATMENT OF STERILITY IN THE MALE
}

\author{
By TERENCE MILLIN, M.Ch., F.R.C.S. \\ (Hon. Surg., All Saints' Hospital for Genito-Urinary Diseases, London; Urologist, Surrey \\ County Council, etc.)
}

It has now been firmly established that the male partner is at least partly responsible in approximately 40 per cent of barren marriages. In every sterile marriage of 2-3 years' duration where help is sought, both partners should be assessed, and the errors, if possible, eliminated. It is important in dealing with these problems that no additional cause be given for increasing marital unhappiness, and unless investigation reveals that one partner is hopeless from a therapeutic standpoint, it is probably wise doctoring to treat both parties. For example, where one finds deficient spermatogenesis, which would appear to be amenable to therapy, some innocuous "treatment," such as vitamin pills, should be administered simultaneously to the wife.

\section{Family History.}

\section{INVESTIGATION OF THE MALE}

Enquiry should be made as to early life, upbringing, number of brothers and sisters, early death of these or of either parent, dissolution of parents' marriage, etc. As there appears to be a definite tendency for some stock to die out, interrogation should ascertain whether there has been intermarriage of blood relations, whether brothers or sisters have offspring, and if so, how many, and how long they were married before pregnancy occurred.

\section{Health, past and present.}

Careful enquiry should be made of past ill-health, especially prolonged debilitating illnesses, swellings or other affections of the external genitalia, operations, in particular those likely to affect the blood supply of the testes, e.g. bilateral herniorrhaphy or radical repair of hydrocoele in childhood. It is noteworthy that orchitis is rarely associated with mumps of childhood, and though not infrequently met with in the adult variety, seldom leads to testicular atrophy. Bilateral orchitis is singularly rare, and so, contrary to common teaching, mumps is an infrequent cause of male sterility (Smith, I937). Congenital syphilitic orchitis is seldom met with to-day, and whilst acquired syphilis would appear to affect the testes early in a high proportion of cases, adequate treatment seems to leave the spermatogenic powers little impaired. Uncomplicated gonorrhoea is an infrequent cause of sterility. Where epididymitis has supervened sterility is a real danger, some 25 per cent of cases of unilateral epididymitis, and 45-90 per cent of bilateral involvement, are left permanently sterile. Tubercular involvement of the genitalia in most cases leads to an eventual sterility.

\section{Congenital Abnormaliites.}

The most important of these is late or non-descent of the testes, and enquiry should be made on this point. It is recognised that many testes will descend into a normal, or relatively normal, position in the scrotum at, or about, the age of puberty, but it appears to be a rarity for those gonads descending after the age of ten to function with normal spermatogenesis. (It is the author's opinion that undescended testes should be left untreated until the age of nine and if then undescended, surgical orchiopexy should be undertaken, care being taken to avoid undue tension in the reposition, proceeding in stages, if necessary, as recommended by Cabot, and studiously preserving all blood vessels in the cord. He does not favour hormone therapy for reasons stated elsewhere.) Hypospadias is another congenital abnormality which, even in the lesser degrees, may minimise the chances of impregnation.

\section{Nature of Occupation.}

Certain industrial diseases have deleterious effects on spermatogenesis, and in some cases a change of employment should be advised. 
General examination.-Evidence of congenital syphilis, nephritis, diabetes, tuberculosis, and endocrine disturbances should be sought.

External genital examination.-Careful inspection and palpation of external genitalia is next made for evidence of hypospadias, fibrous induration of corpora cavernosa, tight foreskin, undescended testes, abnormalities of epididymes, e.g. cysts or loose attachment to testes, soft, small or atrophic testes, thickening of spermatic cords, or more particularly vasa deferentia. Varicocoele, especially when bilateral, appears to be associated with deficient spermatogenesis, though the precise relationship is not clear.

Rectal examination.-The internal genitalia are carefully palpated; evidence of generalised or localised thickening or tenderness of prostate and seminal vesicles may betoken a chronic inflammatory condition, e.g. post-gonococcal, tubercular, or calculous disease of the prostate. Stripping of the prostate and vesicles should then be made, and smears of the secretion thus produced examined microscopically for evidence of pus cells, organisms, etc. If the stained smear shows an excess of leucocytes, a culture of the prostatic secretion should be made to ascertain the nature of the organisms present.

Seminal examination.- This is the next step in the investigation, and certain precautions must be observed in the collection of the specimen if the test is to be of any value. Neither coitus nor a nocturnal emission should have occurred within the preceding five days. The specimen should be collected direct into a dry wide-mouthed glass vessel, preferably obtained by masturbation, or, failing that, by practising coitus interruptus and allowing the emission to occur in the glass vessel provided. In some cases neither of these practices is possible, in which case the specimen should be obtained in a rubber sheath, though it is probable that the effect of the rubber will be to inhibit the motility of the spermatozoa, and on examination the majority, if not all, will be non-motile. The specimen should be in the hands of the examining pathologist as soon as possible after ejaculation, preferably within one hour. The specimen should be transported at room temperature, and precautions to keep it warm (as by means of thermos flask or waistcoat pocket) avoided, as a few degrees above body temperature affects the spermatozoa more adversely than a greater fall of temperature.

The examining pathologist must note:

a. Volume of specimen.

$b$. The $\mathrm{pH}$ of specimen.

c. Percentage motility at I, 6, I2, and, if possible, I 8 hours.

$d$. Percentage of abnormal and premature forms.

$e$. Accurate count estimated in millions per c.c.

$f$. Viscosity and evidence of crystallospermia.

\section{Interpretation of Semen Test.}

Normal.-Volume 2-5 c.cs. Average viscosity. $\mathrm{pH} 7 \cdot 5-8 \cdot 5$. Count not less than 60 million per c.c. Abnormal forms not exceeding 20 per cent Motility at least 70 per cent motile after one hour at room temperature.

Sub-normal.-The commonest form met with is an oligospermia, i.e. diminished count, e.g. Io-20 million per c.c. Such reading must always be interpreted in relation to the total volume of the ejaculation, and is usually associated with deficient motility and increased proportion of abnormal forms.

Testicular biopsy.-Where azoospermia is present and the testes appear clinically normal a testicular biopsy should be made to ascertain whether there is normal spermatogenesis in the gonad. This biopsy is easily made as an out-patient procedure. The spermatic cord is infiltrated, after adequate shaving and skin preparation, with Io c.cs. 2 per cent procaine, which secures anaesthesia of the testis; a suitable spot on the anterior aspect of the scrotum is then selected, and a small wheal raised with a drop or two of the procaine. The testis is then steadied, the anterior aspect of the gonad against this wheal, either by means of a thin rubber tourniquet, or preferably by an assistant, thereby avoiding the congestion consequent on the use of a tourniquet. A small incision I cm. long is then made through the skin and the coverings of the testis until the pearly white tunica albuginea is exposed; this structure is then nicked by means of a small tenotome; the brownish testicular tubules then prolapse through, and by means of a fine 
pair of scissors this prolapsed tissue snipped off and transferred to formol saline, or other fixative, and despatched for microscopy.

A single skin stitch suffices to close the small incision, the ends being tied over a pledget of gauze as an anchor dressing.

\section{TREATMENT}

A. Oligospermia.-The treatment of sub-fertility in the male is not yet founded on a sure basis. In cases where there is only a slight deficiency in spermatogenic activity, simple general tonic measures, holiday, etc., may suffice to restore normality, and where there is a lowered Basal Metabolic Rate the administration of Thyroid may help. Where infection of prostate and vesicles is present a course of prostatic massage with or without Sulpha drug therapy is indicated: Where, however, repeated semen tests reveal a constant deficiency without evidence of constitutional weakness or local inflammations, specific hormone therapy can be of great value. The two main lines of attack are the use of

\section{a. Gonadotropic hormones. \\ b. Androgens.}

Gonadotropic hormones have been recommended by some workers in cases of slight spermatogenic deficiency, and probably are only of value where the hormone is being excreted in subnormal amounts. Reports on their use are not very encouraging. Charny (I944) reviewed I27 cases treated with 400 I-U intravenously 2-3 times weekly over 3-6 months, and noted $9 \cdot 3$ per cent "cured" and I7 per cent "improved." Lack of success with these hormones early led me to abandon their use.

More success appears to follow Androgen therapy. Soifer (I94I) in 22 cases reported 6 pregnancies. Rubinstein (I938) emphasised the desirability of using small doses-a stimulating rather than substitution dose-and recommended 5-Io mmgms. 2-3 times weekly, recalling Kenyon's finding that large doses led to suppression of spermatozoal output. In a personal series of 9I cases of persistent oligospermia treated with $5 \mathrm{mmgms}$. of Testosterone Propionate intramuscularly twice weekly, I8 pregnancies proceeding to term have supervened to date. A six weeks' course is prescribed, and a further semen test made 4 weeks after the conclusion of the course. Such courses are continued until normal figures are obtained, or until it is apparent that no benefit is being derived. The following case is illustrative of the benefit of persistent therapy.

E.L., aet. 37, married I3 years, no pregnancy. Family and past history irrelevant. Examination revealed small soft testes. Semen tests $(a)$ before treatment, $(b)$ after I course of I2 injections, $(c)$ after 3 courses gave the following results:-

Date. $\quad$ Vol. Count.

(a) $8.3 .38 \quad \ldots \quad \ldots \quad \ldots \quad \ldots \quad$ I c.c. $\quad 26$ million

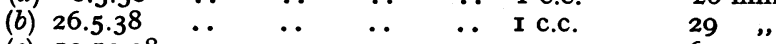

(c) $19.10 .38, \ldots \quad \ldots \quad \ldots \quad \ldots$ r c.c. $\quad 62$,

$\begin{array}{cc}\text { Motility. } & \text { Abnormal forms. } \\ 40 \% & 44 \% \\ 39 \% & 70 \% \\ 60 \% & 15 \%\end{array}$

Pregnancy supervened within 2 months, and proceeded to term, resulting in a $9 \frac{1}{2} \mathrm{lb}$. male child.

\section{B. Azoospermia.} value.

(a) Where the testicular biopsy shows no evidence of spermatogenesis no therapy is of

(b) Where the testicular biopsy reveals normal spermatogenesis there is cogent evidence that a blockage exists in the duct system, i.e. either in the epididymis, vas deferens, or ejaculatory ducts. An exploratory operation may then be indicated, but no very great hopes must be entertained of freeing such obstruction. If such operation is embarked upon, the vas is exposed together with the epididymis. If cysts are present in the latter structure, these should be aspirated, and the aspirated material promptly examined microscopically for evidence of active spermatozoa; the vas is then carefully incised, and a piece of fine silk-worm gut passed along the lumen to ascertain its patency; a fine hypodermic needle, whose point has been blunted, is next threaded over the silk-worm gut and the latter withdrawn; 5 c.cs. of a distinctly coloured fluid, e.g. saline tinted with mercuro-chrome, is then injected along the lumen of the vas. A 
multiple-eyed catheter, some of whose eyes are resting in the prostatic urethra, is then washed through with an ounce of sterile water, and evidence noted of any pink stain indicating the passage of the dye from the vasostomy, and thereby an unobstructed lumen above the epididymis. In the event of such a combination of eventualities, i.e. active sperms in an epididymal cyst and a free lumen above, the vas should be sectioned obliquely close to the epididymis and an anastomosis effected between the cyst and the vas-vaso-epidymostomy-using the very finest suture materials. Where epididymal cysts are not present, attempted anastomosis must be made between the obliquely sectioned vas and the epididymal tubules. Occasionally a stricture may be found in the vas amenable to excision and subsequent end-to-end anastomosis. ' It is the experience of most British urologists (Kidd, Swan, I925) who have undertaken this work that successes are very infrequent, but nevertheless the procedure should not be condemned out of court as several American workers have reported successes, notably McKenna (I9I9), Hagner (I93I).

In conclusion, we must reiterate that in all cases of childless marriage of two years and upwards, a full investigation of the male partner should be made, and where proven deficiency exists, modern therapeutic methods offer at least some hope of success.

\title{
BIBLIOGRAPHY
}

1. CHARNY, J., Amer. Journ. Med. Sc., April 1944.

3. KIDD, SWAN et alii, Proc. Royal Soc. Med. (Sect. Urol.), 18, 56, I925.

4. McKENNA, C. M., Surg. Clinics, Chicago, 3, I45, rgrg.

5. RUBINSTEIN, H. S., Journ. Amer. Med. Assn., Nov. 1938; Southern Med Jour., May 1939

6. SMITH, R. E.,, Guy's Hosp. Repts., Oct. r937.

-7. SOIFER, S., Úrol. and Cutan. Rev., 45, I37, I941.

\section{A NOTE ON THE PROBLEM OF SUBFERTILITY}

\author{
By C. S. LANE-ROBERTS, C.V.O., M.S., F.R.C.O.G. \\ (Gyn. Surg., Royal Northern Hosp., London, etc.)
}

A recent leading article in The Times pointed out that in the I850's there were $18,000,000$ people in England, of whom 2,250,000 were women capable of bearing children, whereas in the I940's there were 4I,000,000 people, of whom just under 10,000,000 were capable of bearing children. Yet in the ten years I933-42 these ten millions have produced 390,000 fewer babies in England and Wales than the $2 \frac{1}{4}$ millions produced in the ten years $I 85 \mathrm{I}-\mathrm{I} 860$.

Thus the existing generation of potential parents, though of record size, will at this present rate grow into a generation of old age pensioners. It is the ageing of our population, with all that it implies in economic policy and in imperial and international affairs, that is a far more serious issue than the total size of our population.

At the other extreme is the condition of India and of its population problem. Professor Blacklock concludes in a recent paper: "If the world achieves lasting peace, if the maximum productive use of land is practised, and if, moreover, there is a sustained effort to apply our knowledge to the betterment of the health of man by attention to the prevention of disease and to improving housing, environment and nutrition, then India, with all these newly-acquired aids towards increase in the numbers and the good health of families, will be so rapidly populated that starvation will inevitably result, and that soon!"

Thus in the British Commonwealth differing methods will be called for in order to deal scientifically with under population on the one hand and over population on the other.

D. V. Glass and C. P. Blacker conclude their Population and Fertility (I938) with the following trenchant sentences: "When we see the causes of declining fertility in their full complexity and discern their manifold groupings and combinations we recognise how enormous is the task of putting really effective counter-measures into operation. Problems of the most imposing character will confront the reformer and the legislator. When we survey the picture of social life in England to-day we are impressed with the number and the excellence of the reasons why married couples should have few children. Again the spread of planned parenthood may 